\title{
The geography and carbon footprint of mobile phone use in Cote d'Ivoire
}

\author{
Vsevolod Salnikov ${ }^{1}$, Daniel Schien², Hyejin Youn ${ }^{3,4,5}$, Renaud Lambiotte ${ }^{1}$ and Michael T Gastner ${ }^{6,7 *}$
}

\author{
"Correspondence: \\ m.gastner@bristol.ac.uk \\ ${ }^{6}$ Department of Engineering \\ Mathematics, University of Bristol, \\ Merchant Venturers Building, \\ Woodland Road, Bristol, BS8 1UB, UK \\ ${ }^{7}$ Institute of Technical Physics and \\ Materials Science, Research Centre \\ for Natural Sciences, Hungarian \\ Academy of Sciences, P.O. Box 49, \\ Budapest, 1525, Hungary \\ Full list of author information is \\ available at the end of the article
}

\begin{abstract}
The newly released Orange D4D mobile phone data base provides new insights into the use of mobile technology in a developing country. Here we perform a series of spatial data analyses that reveal important geographic aspects of mobile phone use in Cote d'Ivoire. We first map the locations of base stations with respect to the population distribution and the number and duration of calls at each base station. On this basis, we estimate the energy consumed by the mobile phone network. Finally, we perform an analysis of inter-city mobility, and identify high-traffic roads in the country.
\end{abstract}

Keywords: mobile phone; Cote d'Ivoire; carbon footprint; human mobility

\section{Introduction}

The availability of mobile phone records has revolutionised our ability to perform largescale studies of social networks and human mobility. Traditionally, researchers had to rely on a combination of surveys, census data and vehicle counting. These methods are costly and time consuming so that data were collected either infrequently or for small population samples only. In the last few years, while searching for innovative methods to circumvent these limitations, researchers have turned their attention to mobile phones as sensors to collect communication and mobility data [1]. The vast majority of studies were carried out in developed countries where mobile communication competes with established landline technologies. However, mobile phones are nowadays commonplace in developing countries too. Especially in Africa, mobile phones now provide affordable telecommunication where no alternative had previously existed $[2,3]$.

The data bases for Cote d'Ivoire, made accessible during the Orange D4D challenge [4], present the first opportunity to analyse a nationwide mobile phone network in Africa. The data are obtained from the so-called Call Detail Records (CDRs) which contain an approximate location of mobile phones every time they connect to a cell tower (e.g. due to a phone call). A growing body of research has shown that CDRs can accurately characterise many aspects of human mobility [5]. Practical examples include the tracking of population displacements after disasters [6, 7], the estimation of traffic volumes in cities [8], the calculation of carbon emissions due to commuting [9] and transport mode inference [10]. CDRs have become the basis for simulating epidemics [11], quantifying linguistic barriers [12] and optimising public transport [13]. Here we apply geospatial techniques to address several questions related to social and economic development. How is mobile phone infrastructure related to its use (Sections 2 and 3)? How much energy is needed to operate

(c) 2014 Salnikov et al.; licensee Springer. This is an Open Access article distributed under the terms of the Creative Commons Attribution License (http://creativecommons.org/licenses/by/2.0), which permits unrestricted use, distribution, and reproduction in any medium, provided the original work is properly cited. 
the network (Section 4)? Is the road infrastructure adapted to the population mobility patterns (Section 5)?

\section{Mapping base station locations with respect to population density}

Where to place the base stations that house the antennas is a central decision for any mobile communication provider. It determines how many people can access the network, the quality of calls and the ease with which the provider can operate the facilities. Optimising the base station locations is a difficult task, complicated by spatially heterogeneous demand and topological obstacles such as tall buildings or mountains. As a rule of thumb, however, population density is a crucial factor: where there are more people, we expect a higher density of base stations. Conversely, if rural areas with lower population are served by a disproportionately low number of base stations, these communities would be left with little or no access to the network. As mobile communication has enormous potential to improve the lives of the rural population (e.g. by access to banking and real-time information about agricultural commodity prices), one development objective must be to provide a roughly equal per-capita number of base stations for the entire population of Cote d'Ivoire.

We map the 1,238 base station coordinates given in the D4D file ANT_POS.TSV on a standard latitude-longitude projection (left map in Figure 1). Since Cote d'Ivoire is close to the equator, such a projection is nearly distance-preserving. The base stations (coloured dots on the map) are spatially very unevenly distributed: in some parts of Abidjan there are more than ten base stations per square kilometre, whereas some subprefectures in the north of the country have no base station at all. That there should be many base stations in Abidjan is quite obvious because $\approx 20 \%$ of all citizens live in the country's most populous city. However, whether the number of base stations is proportional to its population is not immediately apparent from the latitude-longitude projection.

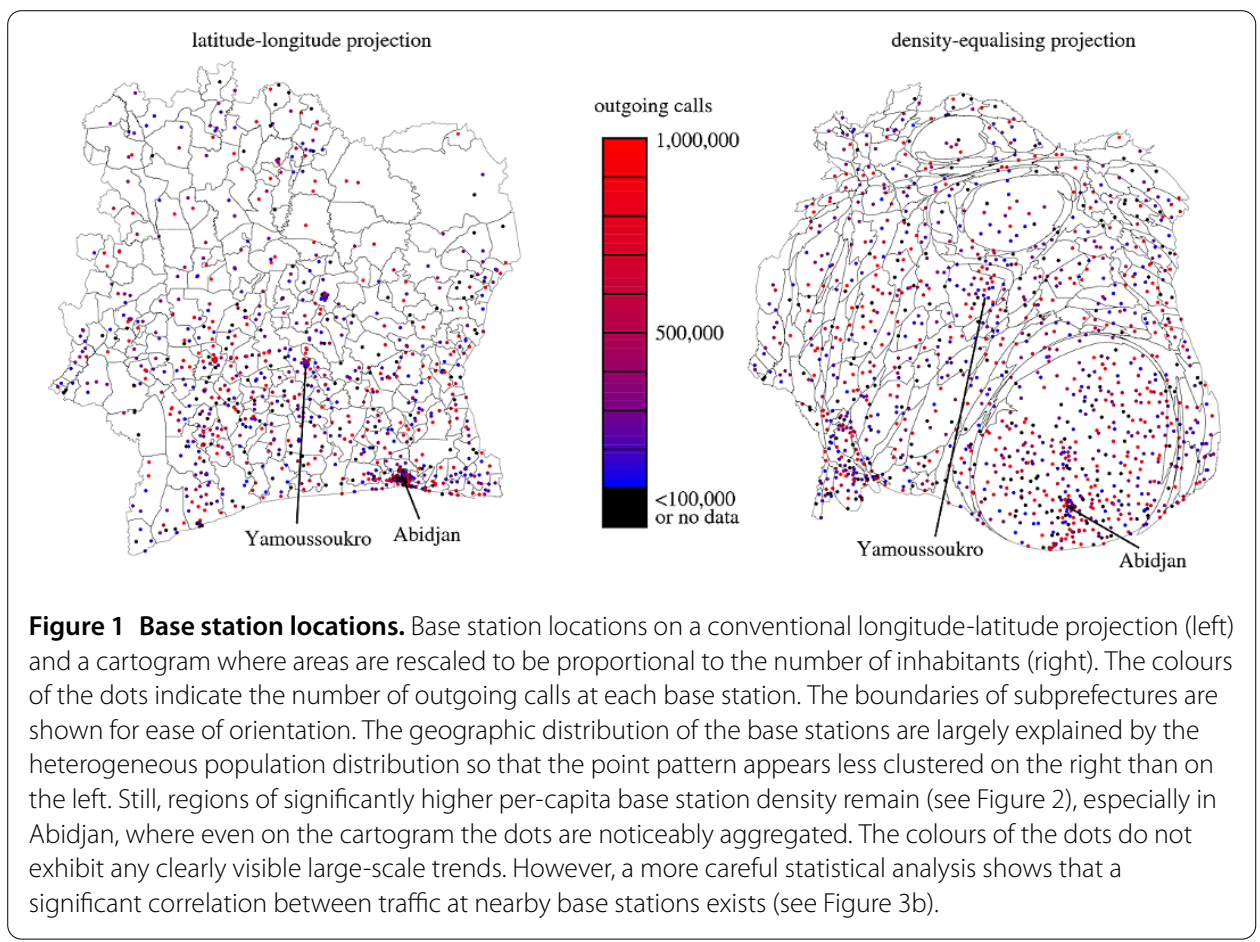




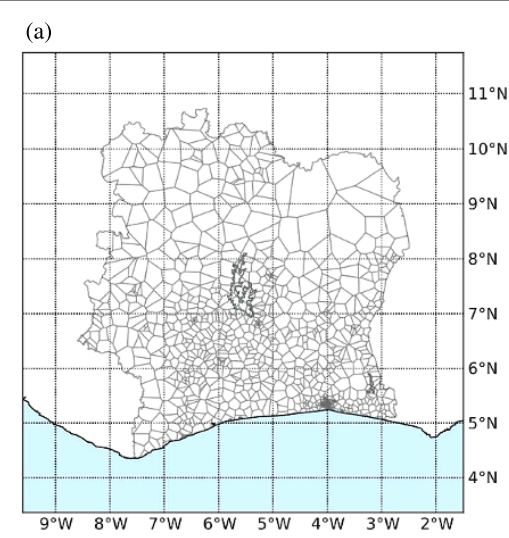

(b)

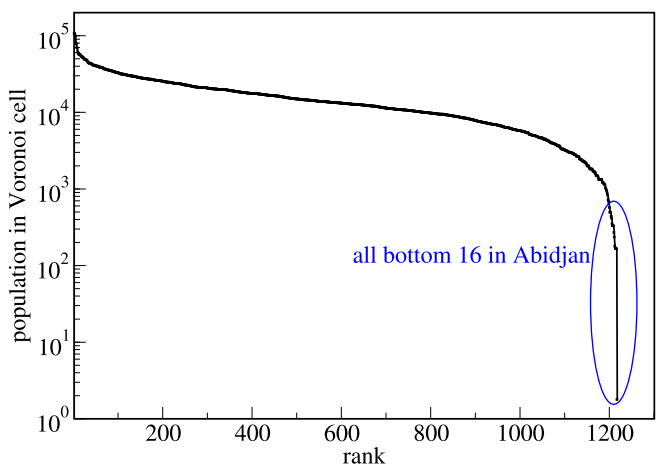

Figure 2 Rank plot of populations in Voronoi cells. (a) Voronoi cells of the 1,217 distinct base station locations in the Orange D4D challenge data base. (b) Rank plot of the population inside the Voronoi cells. Although a majority of 616 cells are within $50 \%$ of the median population (12,897 inhabitants), there are significant outliers at both top and bottom ranks. While the bottom ranked cells are predominantly in Abidjan, the top ranks are in rural areas as well as smaller cities.

We will thus have to combine the base station coordinates with information about the population distribution. Here we use census estimates from the AfriPop project (http://www.afripop.org) [14]. Based on these numbers, we project the map of Ivory coast so that all regions of the country are represented by an area proportional to its population [15]. Such a density-equalising map - also known as a cartogram - has become a popular tool to visualise inequality and development challenges [16]. Plotting the base station locations on the cartogram (right map in Figure 1) reveals a nuanced picture. On one hand, the point distribution is much less aggregated on the cartogram and thus is indeed largely proportional to population. On the other hand, the points are far from a homogeneous pattern. In Abidjan, in particular, a dense cluster of base stations remains clearly visible, indicating a disproportionately high per-capita connectivity there.

We confirm this observation by calculating the population in the base stations' Voronoi cells (Figure 2a). (The Voronoi cell of a given base station is the polygon that contains the area closer to this base station than to any other.) A population-proportional base station distribution would result in an equal population inside each Voronoi cell. A rank plot of population numbers (Figure $2 \mathrm{~b}$ ), however, has a clear S-shape: although most cells have a population of around 15,000 (mean 15,500, median 12,897), there are outliers in both directions. Interestingly, the 16 lowest ranked cells are all in Abidjan, making it by far the region with the highest per-capita base station density. By contrast, the Voronoi cells with the largest populations are in rural areas near inland borders (e.g. the second ranked base station at $7.267^{\circ} \mathrm{N}, 8.160^{\circ} \mathrm{W}$ is $20 \mathrm{~km}$ east of the Liberian border and the fifth ranked at $9.803^{\circ} \mathrm{N}, 3.303^{\circ} \mathrm{W}$ is $6 \mathrm{~km}$ south of the border with Burkina Faso) or near smaller cities (the top and third ranked base station are only a few kilometres outside Bouaké and the fourth and sixth ranked near Korhogo, the country's third and seventh largest cities respectively). Because many facility location models suggest that a fair distribution of resources should intentionally be skewed in favor of less populated areas [17, 18], our finding suggests these regions as targets for a future expansion of the network. 
3 Spatial correlation between the population density and the number of calls Recent studies of mobile phone records in developed countries [19] have argued that the number of human interactions in cities increases faster than linearly with the city population. This poses the question: does the number of calls in Cote d'Ivoire depend similarly on population density? We count the population and the number of calls on a square grid. We investigate squares of size $5 \mathrm{~km} \times 5 \mathrm{~km}, 10 \mathrm{~km} \times 10 \mathrm{~km}$ and $20 \mathrm{~km} \times 20 \mathrm{~km}$. We generally find that the number of calls is less correlated for smaller than for larger populations so that we divide the data into two distinct regions: one for sparsely and another for densely populated squares. We show the results for ordinary least-squares fits of the form $\log ($ number of calls $)=a \log ($ population $)+b$ in Figure $3 \mathrm{a}$ for the $5 \mathrm{~km} \times 5 \mathrm{~km}$ grid. ${ }^{\mathrm{a}}$ In the densely populated regime (population $>10,000$ ), regression yields a slope $a=0.87$ with a $95 \%$ confidence interval $[0.70,1.03] .{ }^{\mathrm{b}}$ (The formula for computing confidence intervals can be found for example in [20].) For larger sizes $(10 \mathrm{~km} \times 10 \mathrm{~km}, 20 \mathrm{~km} \times 20 \mathrm{~km})$ the least-squares exponent for dense populations increases, but all $95 \%$ confidence intervals include 1, the dividing line between sub- and superlinear scaling (see Table 1). This finding remains true even if the call intensity is measured by the total duration rather than the number of calls. Hence, the available data give neither sufficient evidence for nor against superlinear scaling for large populations.

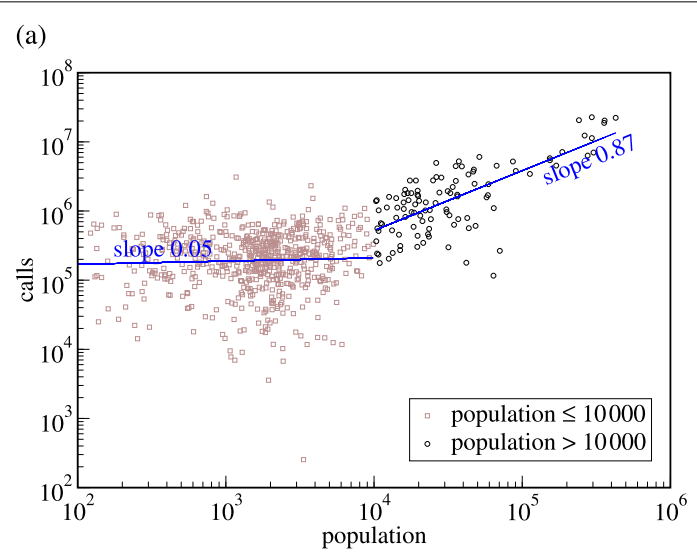

(b)

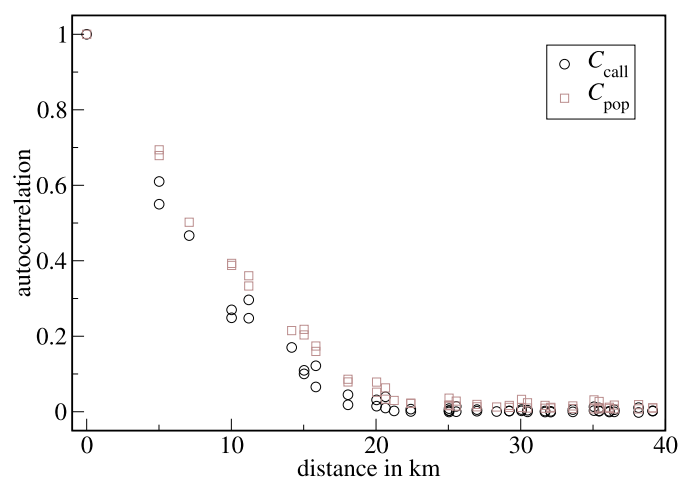

Figure 3 Correlation between population and phone call intensity. (a) Scatter plot of the total number of outgoing calls versus the population. Both variables are counted on a $5 \mathrm{~km} \times 5 \mathrm{~km}$ square grid. An ordinary least-squares fit yields different slopes for small and large populations. (b) The spatial autocorrelation functions for the number of calls and the population size exhibit significant non-zero correlations up to $\approx 15 \mathrm{~km}$. 
Table 1 Regression of call intensity versus population

\begin{tabular}{|c|c|c|c|c|c|}
\hline \multirow[t]{2}{*}{ Grid } & \multirow[t]{2}{*}{ Intensity } & \multicolumn{2}{|c|}{ Small population } & \multicolumn{2}{|c|}{ Large population } \\
\hline & & $a$ & $95 \% \mathrm{Cl}$ & $a$ & $95 \% \mathrm{Cl}$ \\
\hline $5 \mathrm{~km} \times 5 \mathrm{~km}$ & $\begin{array}{l}\text { number of calls } \\
\text { duration of calls }\end{array}$ & $\begin{array}{l}0.05 \\
0.06\end{array}$ & $\begin{array}{l}{[-0.04,0.13]} \\
{[-0.02,0.14]}\end{array}$ & $\begin{array}{l}0.87 \\
0.86\end{array}$ & $\begin{array}{l}{[0.70,1.03]} \\
{[0.70,1.02]}\end{array}$ \\
\hline $10 \mathrm{~km} \times 10 \mathrm{~km}$ & $\begin{array}{l}\text { number of calls } \\
\text { duration of calls }\end{array}$ & $\begin{array}{l}0.06 \\
0.08\end{array}$ & $\begin{array}{l}{[-0.05,0.17]} \\
{[-0.03,0.18]}\end{array}$ & $\begin{array}{l}1.00 \\
1.01\end{array}$ & $\begin{array}{l}{[0.77,1.23]} \\
{[0.78,1.23]}\end{array}$ \\
\hline $20 \mathrm{~km} \times 20 \mathrm{~km}$ & $\begin{array}{l}\text { number of calls } \\
\text { duration of calls }\end{array}$ & $\begin{array}{l}0.27 \\
0.28\end{array}$ & $\begin{array}{l}{[0.11,0.43]} \\
{[0.12,0.43]}\end{array}$ & $\begin{array}{l}1.24 \\
1.27\end{array}$ & $\begin{array}{l}{[0.91,1.57]} \\
{[0.93,1.60]}\end{array}$ \\
\hline
\end{tabular}

Results of regression to $\log ($ intensity $)=a \log$ (population) $+b$. The cutoff between small and large populations is 10,000 for the $5 \mathrm{~km} \times 5 \mathrm{~km}$ grid, 20,000 for the $10 \mathrm{~km} \times 10 \mathrm{~km}$ grid and 40,000 for the $20 \mathrm{~km} \times 20 \mathrm{~km}$ grid. The cutoffs were chosen so that the number of data points in the large population regime are approximately equal (105, 74 and 80 respectively).

For small populations, however, superlinear scaling can be firmly ruled out. In this regime, the least-squares exponents for the $5 \mathrm{~km} \times 5 \mathrm{~km}$ and the $10 \mathrm{~km} \times 10 \mathrm{~km}$ grids are not even significantly different from zero, so that population hardly influences the call intensity at all. The explanation lies in infrastructure located away from population centres. Among the $5 \mathrm{~km} \times 5 \mathrm{~km}$ squares with a population below 10,000, three of the ten squares with the largest number of calls are near the Buyo hydroelectric plant $\left(6^{\circ} 14^{\prime} \mathrm{N}\right.$, $7^{\circ} 3^{\prime} \mathrm{W}$ ). The other seven squares in the top ten are near major highways (San Pedro Betia Road, San Pedro - Tabou Road, A4, A6, A7, A8 and A100). These locations are in zones with low population density, but the local infrastructure generates a relatively high call intensity.

Despite the weak correlation between calls and population size, the spatial distribution of calls is far from random. In Figure $3 \mathrm{~b}$ we plot the spatial autocorrelation function $C_{\text {call }}$ on the $5 \mathrm{~km} \times 5 \mathrm{~km}$ grid. Although $C_{\text {call }}$ decays quickly, the correlation is nevertheless $>0.1$ up to a distance of $\approx 15 \mathrm{~km}$. For comparison, we also plot the autocorrelation $C_{\text {pop }}$ of the population. $C_{\text {pop }}$ is generally a little larger than $C_{\text {call }}$, but it decreases at a similar rate. It remains an intriguing question for future research whether both autocorrelations are generated by similar social mechanisms. In particular, an analysis based on a more careful socio-economic definition of 'city size' [21] may still unearth more details.

\section{Energy and carbon footprint of wireless cellular networks in Cote d'Ivoire}

In this section we estimate the energy and greenhouse gas (GHG) emissions, contributing to climate change, of the wireless cellular network in Cote d'Ivoire and compare its share of the national GHG emissions with that of wireless networks in other countries.

While mobile network operators are increasingly transparent about their environmental impact and GHG emissions, few data are available about the energy consumption and resulting GHG emissions of mobile networks in developing countries. Moreover, the Orange Cote d'Ivoire (OCI) data permits discussing energy consumption of parts of the entire network in relationship to population density. Thus, this work contributes to ongoing research that investigates the direct environmental impact of ICT (Information and Communication Technology) of systems in general, independent of development contexts, by estimating an entire network's footprint from the number of its base stations.

Much research has shown that mobile technologies are an important instrument of current information and communication technologies for development (ICT4D) strategies, for example [22]. On the other hand, the increasing deployment of these technologies can result in increasing GHG emissions, sometimes labelled 'footprint', which recently has also 
received increasing interest by the community of ICT4D researchers [23, 24]. It is our aim to contribute to a more informed discussion through provision of quantitative estimates of energy consumption and GHG emissions. We want to precede this analysis with a qualification: in or outside of a development context the analysis of environmental impact of a technical system and its results can stand separately from the interpretation of these results towards decision making for policy formation. In this text we estimate the annual GHG emissions of the mobile network in Cote d'Ivoire and suggest directions for existing or future development of these networks from the perspective of their technical operation. However, this analysis would only provide an incomplete basis for policy making towards a development strategy as it does not include an analysis of the social or economic impacts and benefits of the wireless network.

The goal of our assessment is to estimate the national energy consumption and GHG emissions using the number of base stations as an input parameter. This requires an estimate of the power consumption per base station and the overhead from the remaining parts of the network. Depending on its type, the power consumption of a base station can vary between 800 and 2,800 W (estimations presented in [25]). Without additional information about the specific types of base stations, the OCI data can only be parameterised with average data. Additionally, an assessment of the energy consumption of a mobile network should include all relevant system parts in order to enable greater transferability of results. We assume the following composition of the wireless network: the base stations, which house the antennas and amplifiers, and auxiliary equipment for cooling and power transformation provide the radio signal to subscribers. They are controlled by several base station controllers and a few mobile service centres to which they are connected via a radio or fixed network. This network also provides connectivity with the Internet or networks of other operators. In our estimate of the GHG emissions we had to make some simplifying assumptions about the network infrastructure. We estimated the energy consumption for a single base station (including overhead for other system parts such as base station controllers) of around 2,100 W based on similar assumptions made in [25] and [26] that are based on publicly available data by Vodafone. This value is a top-down estimate based on the total energy consumption of the network and the total number of base stations. The corporate responsibility report of the Vodafone Group states that in 2011 the company globally operates 224,000 base stations and that the energy consumption was 4,117 GWh [27]. This value does not account for energy consumption in offices. Given that the average power consumption per base station is around $1.5 \mathrm{~kW}$, the resulting value of 2,100 W per base station is plausible and further corroborated by other studies such as [28] who state that the energy consumption of the base stations constitutes $60-80 \%$ of the total energy consumption of the network.

An estimate of the contribution of the remaining parts of a mobile operator's organisation to energy and carbon footprint can, for example, be based on corporate social responsibility reports by Vodafone and O2, which state that the network accounts for around $80 \%$ to $90 \%$ of an operator's energy consumption $[29,30]$ and constitutes a similar portion of its GHG emissions [31]. The GSMA Mobile Green Manifesto report [32] makes similar assumptions. We assume that these ratios also apply to the OCI network and networks of other operators in Cote d'Ivoire.

Based on the data inventory we have a precise count of mobile base stations $(1,238)$. In order to estimate the total annual national energy consumption by mobile networks we 
had to also estimate the number of base stations by competitors of OCI in addition to the power consumption by the other system parts. We assumed that all mobile operators deploy their network on average with similar density. Based on the market share of subscriptions (between 33\% OCI [33] and 35\% [34]) we estimate that the total number of base stations in Cote d'Ivoire is around 3,700.

Given these assumptions, we estimate that the GHG emissions of the wireless mobile networks by all operators in Cote d'Ivoire amount to about 29.1 kilo tonnes carbon dioxide equivalent per year $(\mathrm{ktCO} 2 \mathrm{e})$. This is about $0.4 \%$ of the total annual carbon emissions of $6,596.933 \mathrm{ktCO} 2 \mathrm{e}$ [35]. We further estimate the energy consumption to be $68 \mathrm{GWh}$ which is about $1.9 \%$ of the total annual energy production of Cote d'Ivoire [36]. Compared to the pro-rata energy consumption and GHG emissions by mobile networks in Germany, this value is relatively high. Based on publicly available data by Vodafone Germany energy consumption by the network accumulated circa $600 \mathrm{GWh}$ [30] in 2011. Assuming other wireless networks are equally efficient and Vodafone's market share of $32.97 \%$ [37], the energy consumption by mobile networks in Germany would be about $0.3 \%$ of the absolute energy consumption in the country in 2011 [38]. In [32] it is found that on global average, mobile networks result in $0.2 \%$ of all GHG emissions. Based on the Vodafone data, however, the portion of German mobile networks of the national GHG emissions is only around $0.1 \%$.

Given the lack of data on the power consumption by each base station, there is a relatively high uncertainty to the estimate of the total annual energy consumption by all networks. The estimate of the carbon emissions is further affected by uncertainty in the parameter for the carbon intensity of electricity. In OECD countries, base stations are typically operated with energy from the electrical grid. In developing countries, however, electrical energy is possibly supplied by diesel generators to a significant degree. Diesel generators result in a greater carbon intensity per generated $\mathrm{kWh}$ of electricity $(0.788 \mathrm{kgCO} 2$-eq $/ \mathrm{kWh}$ [39], as compared to $0.426 \mathrm{kgCO} 2-\mathrm{eq} / \mathrm{kWh}$ of the average intensity of grid electricity).

In Table 2 we evaluate the influence of these parameters on the estimates of GHG emissions and energy consumption. In scenario I, we consider how the energy consumption and GHG emissions would change if the average power consumption per base station was reduced by $25 \%$ relative to our base line. The resulting average power consumption per base station, including a portion for remaining network parts, is $1.58 \mathrm{~kW}$. In this case the carbon footprint of the network is $0.33 \%$ and slightly closer to the global average value estimated by GSMA in [32] of $0.2 \%$.

Table 2 Energy consumption of Cote d'Ivoire's mobile phone network

\begin{tabular}{lrrr}
\hline & BASE & I & II \\
\hline Carbon intensity of electricity (kgCO2e/kWh) & 0.43 & 0.43 & 0.60 \\
Average aggregate power consumption per BS (kW) & 2.10 & 1.58 & 2.10 \\
Total national energy consumption by mobile networks (GWh) & 68.32 & 51.24 & 68.32 \\
National energy consumption by mobile networks (percent of total) & 1.90 & 1.43 & 0.95 \\
Total national GHG emissions by mobile networks (ktCO2e) & 29.11 & 21.83 & 41.13 \\
National GHG emissions by mobile networks (percent of total) & 0.44 & 0.33 & 0.62 \\
Annual energy consumption per subscriber (kWh/sub) & 3.83 & 2.88 & 3.83 \\
\hline
\end{tabular}

Scenarios of alternative input parameters. Scenario 'base' assumes average values for all parameters, scenario 'l' assumes a value for the power consumption per base station compared to $25 \%$ from base. Scenario 'Il' assumes that $50 \%$ of the electricity consumed by base stations is supplied by diesel generators. 
Secondly, we evaluate the scenario that half of the electricity consumed by the base station was provided by diesel generators and the other half by the electrical grid which would increase the carbon intensity from $0.426 \mathrm{kgCO} 2 \mathrm{e} / \mathrm{kWh}$ to $0.602 \mathrm{kgCO} 2 \mathrm{e} / \mathrm{kWh}$. We include the assumption that this would free capacity in the electrical grid. In our scenario, the mobile network would consume $0.95 \%$ of Cote d'Ivoire's electrical energy and constitute $0.62 \%$ of the national GHG emissions. We also considered evaluating more complex assumptions about the types of base stations. Such a scenario would assume that network planners generate relatively precise predictions of demand in a cell. However, the number of outgoing calls that we plot in Figure 1 together with incoming calls are only a possible proxy to overall demand of voice traffic. Data services and number of calls at peak time must both be considered to estimate the minimum capacity of a base station. We believe that the results of such a scenario would have too much uncertainty to bring significant value for our discussion.

Given this sensitivity analysis it remains clear, that mobile networks in Cote d'Ivoire contribute to a greater degree to the total GHG emissions of the country than those in Germany. One of the main reasons for this difference is likely to be the contrasting structure of the German and Ivorian economy to which the energy intensive manufacturing industry in Germany is likely to contribute. This assumption is also supported by a comparison of street lighting as another energy consuming infrastructure. A report by the World Bank mentions in passing that 400,000 public street lights are operated in Cote d'Ivoire [40]. Assuming that street lights have a power consumption between 35 and $400 \mathrm{~W}$ [41] each, they constitute a share of the total energy consumption in Cote d'Ivoire between 1.4 and 16 percent. In contrast, the street lighting in Germany constitutes only $0.56 \%$ of the total energy consumption [42].

Interestingly, if apportioned to each subscriber, the annual energy consumption of the OCI mobile network is $3.83 \mathrm{kWh} / \mathrm{sub}$ which is much lower than the same metric for customers of Vodafone Germany $(16.5 \mathrm{kWh} / \mathrm{sub})$. The value is also a lot lower than the values reported in [43] (values between 7 and $34 \mathrm{kWh} / \mathrm{sub}$ with an average of $16.7 \mathrm{kWh} / \mathrm{sub}$ ). In the case of Cote d'Ivoire, this is likely to be partly the result of a sparser deployment of base stations, in particular outside of Abidjan as we illustrate in Section 2. One contributing factor to this sparser deployment is likely to be the lower degree of urbanisation (52\% compared to $74 \%$ Germany [35]). Another factor is the delayed introduction of data services to Cote d'Ivoire. Third generation services are only just being introduced to this market. Energy consumption on the user side of the mobile network by mobile phones and chargers is significantly lower than this. Phone models such as the Nokia 108 DualSim [44] draw a power between as little as $5.86 \mathrm{~mW}$ and about $0.254 \mathrm{~W}$ while talking. Estimating the total energy consumption over the year depends on the user behaviour but even if customers spent $1 \mathrm{~h}$ talking on the phone per day, which is about 4 times higher than the average time spent in Europe, the total energy consumption by the phone would be about $0.18 \mathrm{kWh}$ which is about $5 \%$ of the per-user energy consumption by the equipment on the operator side. Similarly, the energy consumption by chargers will vary if they remain plugged in while not connected to the phone. Yet, even if they are never disconnected, their power draw would result in a total energy consumption of $0.876 \mathrm{kWh}$ which is about $23 \%$ of the operator side equipment.

These figures have relevance to the ICT4D community because development in Cote d'Ivoire can be seen as indicative for many other African countries. Cote d'Ivoire currently 
is among the countries with the highest mobile phone penetration [45]. As our estimates illustrate, the uptake of mobile phone technologies is accompanied by an increase in energy consumption. For Cote d'Ivoire specifically, it is likely that the energy consumption by the network will increase in the near future with an increasing adoption of data services.

Meanwhile, network coverage in Cote d'Ivoire is not homogenous as was described in Section 2. The Voronoi plot of the country in Figure 2a shows that the Voronoi cells around base stations are significantly larger in the region north of the 8th degree latitude. Indeed, the average population per cell in this northern region is 26,405 while it is 14,414 in the south. A further 94 base stations were needed in the north in order to achieve the same population density per base station which would increase the energy consumption in Orange's network by $7.6 \%$.

\section{Detecting important routes for inter-city mobility}

CDRs provide a cheap and efficient source of data to study human mobility patterns at a large scale [1]. Yet they suffer from limitations that need to be carefully considered, and in some case dealt with, to ensure the validity of the observations. A key limitation is the sparse and heterogeneous sampling of the trajectories, as the location is not continuously provided but only when the phone engages in a phone call or a text message exchange. Moreover, the spatial accuracy of the data is determined by the local density of base stations. When estimating mobility from CDRs, different approaches have been developed in the literature (see Figure 4 for illustration).

First, researchers interested in statistical models of human mobility have adopted a Brownian motion approach [46], where each individual is considered as a particle randomly moving in its environment. Mobility is considered as a path between positions at successive position measurements. Authors have observed statistical properties reminis-

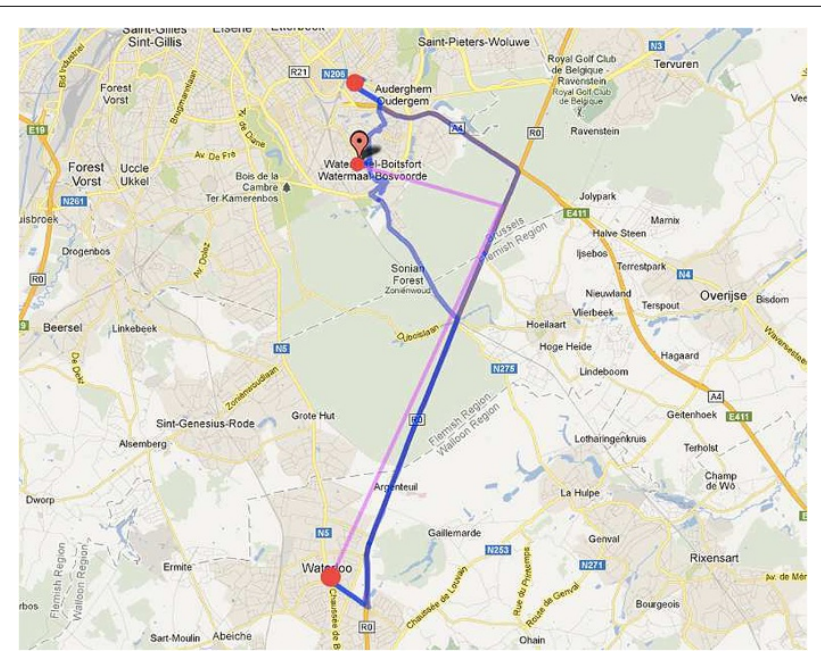

Figure 4 Detecting mobility patterns. To illustrate the different ways to uncover mobility patterns from CDRs, let us focus on the motion of an individual in Brussels, as measured by his GPS. In this small experiment, the user took his car in Watermael and went to two shops, one in Auderghem and one in Waterloo. The three locations are plotted in red. Three phone calls were made. One at home, one on the highway, and one in Waterloo. An approach where a path is composed of successive position measurements is shown in pink. In contrast, an approach where paths are based on important locations would detect the stop in Waterloo, rightly discard the one on the highway, but would still be blind to the location in Auderghem, because that stop was too short. 


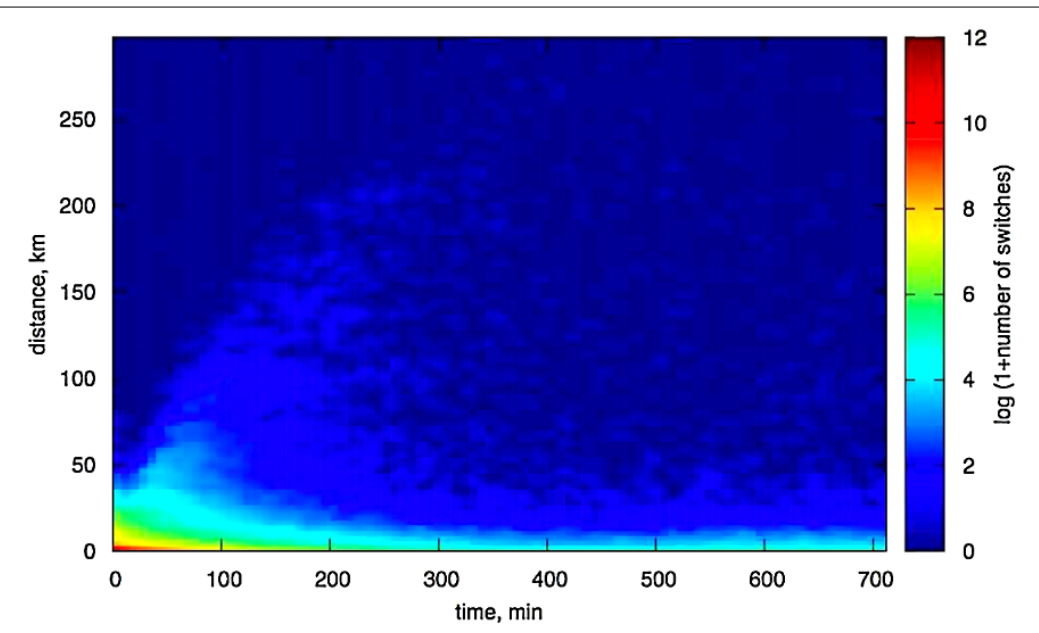

Figure 5 Traveled distance versus travel time. Heat map of the distances and time intervals between consecutive CDRs in the D4D dataset. The burstiness of phone activity leads to a broad distribution over time. Keeping transitions from different regions in the two-dimensional space allows for the identification of different aspects of human mobility.

cent of Levy flights, together with a high degree of regularity. Yet, the usefulness of these observations is limited by the bursty nature of phone activity, as burstiness is expected to alter basic statistical properties of the jumps, such as their distance distribution (see Figure 5). Even in studies where the positions are evaluated at regular intervals, the nature of the jumps remains unclear, as the method tends to detect short trips due to localisation errors, and is blind to the type of the places sampled from the real trajectory. As a side note, let us mention recent work using geo-localised web services, such as Foursquare, where users voluntarily check-in at places $[47,48]$. Foursquare check-ins are also characterised by a bursty behaviour, but they provide a GPS accuracy, and semantic information (at the office, travelling, etc.) that might solve the aforementioned problems.

The second approach relies on the idea that mobility consists of moving from one place to another. The observation of mobility patterns thus requires one to define and identify important locations. A trajectory is seen as a set of consecutive locations visited by the user. Important locations can either be defined as a place where a user spends a significant amount of time, which he visits frequently, or where he has stopped for a sufficiently long time $[1,49-51]$. This approach provides a more intuitive picture of mobility, where the sampling is determined by the periods of rest of the user. However, it is blind to the multiscale nature of human mobility, as it requires the parametrisation of thresholds in time and in space to identify important locations. The value of the threshold and the corresponding granularity of the places depends on the system under scrutiny, say cities for international mobility or rooms for human mobility inside hospitals [52].

When measuring human mobility from CDRs, it is important to remember that mobility is about space and time. Both aspects must be carefully considered to provide a faithful description of human trajectories, especially in situations where the sampling of the data is heterogeneous. For this reason, each transition should be remembered as a jump in space over an interval in time and, if possible, be put in relation to the previous and following transitions. Contrary to the universality viewpoint of [46], not all transitions are alike. On the contrary, it is possible to extract different information and different types of mobility 
patterns by focusing on different regions in space-time. This filtering has been adopted in various studies, but usually either in space or in time. Let us mention [51], where transitions between identified places are considered only if they are registered within two hours of each other; in [50] the daily range of mobility is calculated, and in [8] a trip is defined as a displacement between two distinct base stations occurring within one hour in each time period. More complex filters can be defined on so-called handoff patterns, that is a sequences of cell towers that a moving phone uses while engaged in one voice call, e.g. in [49] where only sequences of more than 5 cell towers are included. Let us note that a filtering in space and in time allows for the selection of a characteristic velocity and, if needed, of the removal of noisy transitions occurring at a small spatial scale, e.g. transitions between neighbouring cells of a static user, or long temporal scale, e.g. transitions over several days where several intermediate steps are expected to be missing.

This overview of recent research suggests direct applications that would be of particular interest in a developing country, where empirical data on human mobility tend to be lacking. Using the aforementioned methodologies, it would be possible, for instance, to identify and map nationwide commuting patterns. Traffic tracking and route classification would also be possible after additional data is collected from test drives or signal strength data collected by high-resolution scanners [49]. In this work, we illustrate the potential benefits of a CDR analysis by focusing on the detection of high-traffic roads between cities. Such a detection might help deploy new infrastructure where the population actually needs it, e.g. in regions where mobility is high but the infrastructure is poor. Finding high-traffic roads requires one to filter transitions in the two-dimensional space of Figure 5. To do so, we apply the following procedure. We consider only transitions in a certain velocity range and occurring in less than a predefined time interval. Our choice of velocity range for car mobility is $[15,150] \mathrm{km} / \mathrm{h}$, in order to discard pedestrian motion and noisy points, i.e. due to antenna switching instability. For our analysis, we have used the data from POS_SAMPLE_X.TSV source files, containing separate users' traces, in the form of a list of user - antenna - timestamp for each call or SMS, together with the antenna positions from the ANT_POS.TSV file. The lower bound for the time interval between two points has been set as the minimal value between two actions. For the upper bound, a one hour limit has been chosen in order to balance between sufficient data points and accuracy. Moreover, to remove noisy connections and to identify persistent motion, we have removed weak transitions between antennas, i.e. occurring less than 10 times. This operation leads to a fragmentation of the network into connected components which we further exploit by keeping only components composed of at least ten vertices. This operation has the advantage of removing undesired connections due to antenna switching and not associated to motion. Our results are robust under variations of the above parameters.

The described technique gives a good approximation of the most important human migration pathways (see Figure 6) and thus can be used for alternative road construction or improvement. Interestingly, it also allowed us to identify unknown roads, which we could validate a posteriori. Examples are shown in Figure 7 and Figure 8 where roads that were absent in Microsoft maps but found by our algorithm are found in maps provided by OpenStreetMap and Yahoo respectively. This can be of particular interest for a semiautomated map improvement technique: if a strong connection is found from the CDR information, but there is no road on the map, it should be analysed carefully whether an existing road has so far been overlooked. 


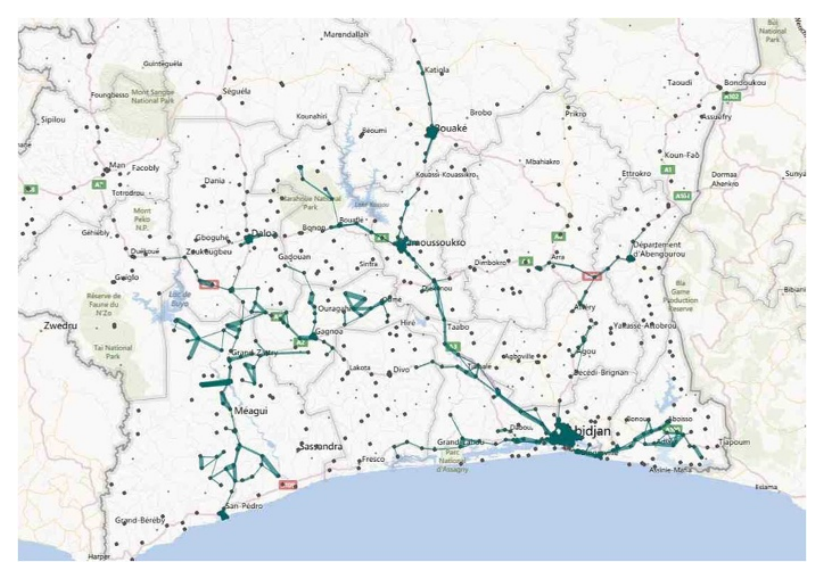

Figure 6 High-traffic roads from mobile phone records. High-traffic road detection, as obtained from CDR data.

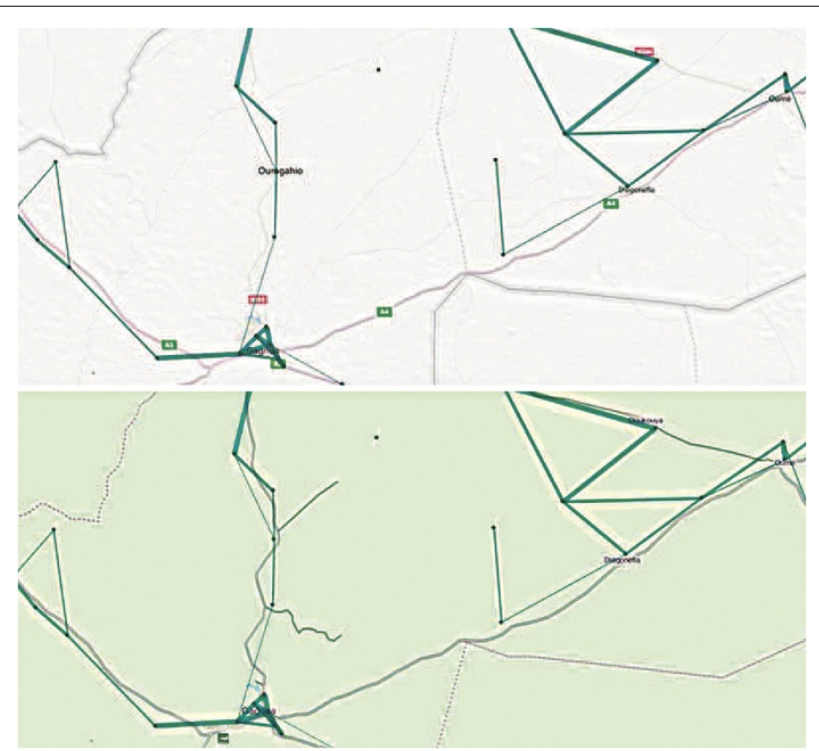

Figure 7 Road identification on Microsoft and OpenStreetMap maps. Roads that are identified from CDR data and are absent on a Microsoft map (upper panel) can be identified on an OpenStreetMap (lower panel).

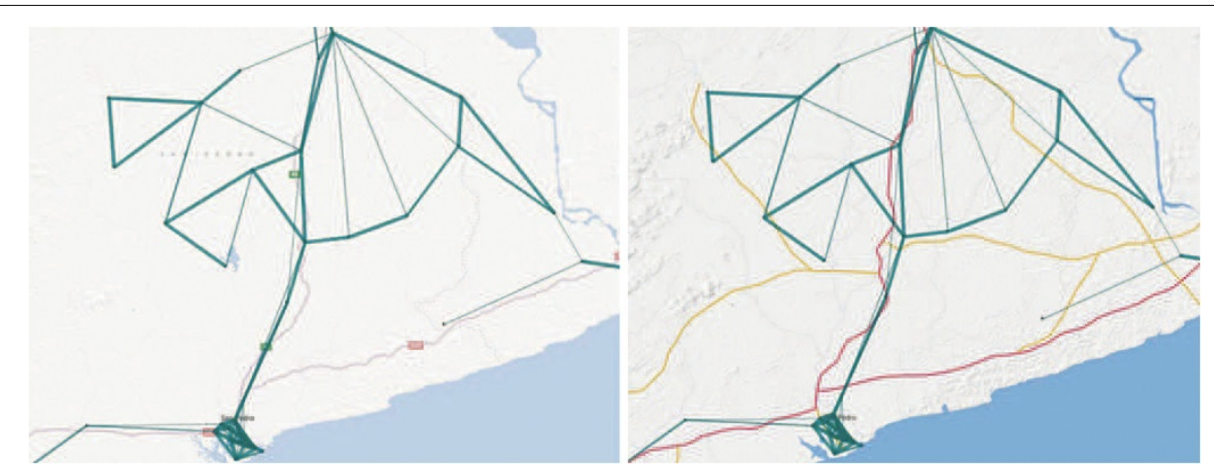

Figure 8 Road identification on Microsoft and Yahoo maps. Roads that are identified from CDR data and are absent on a Microsoft map (left panel) can be identified on a Yahoo map (right panel). 


\section{Conclusion}

In this article we have presented how an analysis of the Orange D4D mobile phone data base reveals important patterns of communication infrastructure and mobile phone use in Cote d'Ivoire. The placement of base stations is biased towards Abidjan so that one development goal is an enhancement of the network in smaller cities and rural regions. We estimate that the network currently consumes between 2.88 and $3.83 \mathrm{kWh}$ of energy annually per subscriber. Although this figure is less than in an industrial country such as Germany, the fraction of the national energy consumption spent on mobile telephony (estimated between $0.95 \%$ and $1.90 \%$ ) is actually higher. Finally, we argued that mobility data from CDRs need further filtering to extract truly meaningful commuting patterns. We used the mobility traces that were part of the Orange D4D database to demonstrate how the main roads in Cote d'Ivoire can be identified.

\section{Competing interests}

The authors declare that they have no competing interests.

\section{Authors' contributions}

MTG performed the analysis of base station locations. HY and MTG calculated the correlation between phone calls and population density and drafted the text of Sections 2 and 3. DS calculated the energy consumption and drafted Section 4. VS performed the analysis of mobility traces. VS and RL drafted Section 5. All authors reviewed and approved the complete manuscript.

\section{Author details \\ 1 naXys, University of Namur, Rempart de la Vierge 8, Namur, 5000, Belgium. ${ }^{2}$ Department of Computer Science, University of Bristol, Merchant Venturers Building, Woodland Road, Bristol, BS8 1UB, UK. ${ }^{3}$ Santa Fe Institute, 1399 Hyde Park Road, Santa Fe, NM 87501, USA. ${ }^{4}$ Institute for New Economic Thinking, Oxford Martin School, Walton Well Rd, Oxford, OX2 6ED, UK. ${ }^{5}$ Mathematical Institute, University of Oxford, Oxford, UK. ${ }^{6}$ Department of Engineering Mathematics, University of Bristol, Merchant Venturers Building, Woodland Road, Bristol, BS8 1UB, UK. ${ }^{7}$ Institute of Technical Physics and Materials Science, Research Centre for Natural Sciences, Hungarian Academy of Sciences, P.O. Box 49, Budapest, 1525, Hungary.}

\section{Acknowledgements}

We thank Orange for making the D4D data set available. VS and RL acknowledge financial support from FNRS. MTG is grateful for financial support from the University of Bristol and the EPSRC Building Global Engagements in Research (BGER) grant. He also acknowledges support from the European Commission (project number FP7-PEOPLE-2012-IEF 6-456412013). This paper presents research results of the Belgian Network DYSCO (Dynamical Systems, Control, and Optimization), funded by the Interuniversity Attraction Poles Programme, initiated by the Belgian State, Science Policy Office. HY acknowledges the support by grants from the Rockefeller Foundation and the James McDonnell Foundation (no. 220020195)

a Five kilometres is approximately the reception radius of a base station, which is the relevant length scale in this problem. However, we also state the results for the other grids in Table 1.

b Because the logarithm of zero is undefined, the regression is calculated by ignoring cells where there were no calls.
}

Received: 15 August 2013 Accepted: 5 February 2014 Published: 19 February 2014

References

1. Becker R, Cáceres R, Hanson K, Isaacman S, Loh JM, Martonosi M, Rowland J, Urbanek S, Varshavsky A, Volinsky C (2013) Human mobility characterization from cellular network data. Commun ACM 56:74-82

2. Heeks R, Jagun A (2007) Mobile phones and development. id21 insights 69:1-2. Available at http://www.dfid.gov.uk/r4d/PDF/Articles/insights69.pdf

3. Singh R (2009) Mobile phones for development and profit: a win-win scenario. Overseas development institute opinion 128. Available at http://www.odi.org.uk/sites/odi.org.uk/files/odi-assets/publications-opinion-files/3739.pdf

4. Blondel VD, Esch M, Chan C, Clerot F, Deville P, Huens E, Morlot F, Smoreda Z, Ziemlicki C (2012) Data for development: the D4D challenge on mobile phone data. arXiv:1210.0137

5. Hoteit S, Secci S, Sobolevsky S, Pujolle G, Ratti C (2013) Do mobile phone data allow estimating real human trajectory? In: Proc. of 3rd int. conference on the analysis of mobile phone datasets

6. Bengtsson L, Lu X, Thorson A, Garfield R, von Schreeb J (2011) Improved response to disasters and outbreaks by tracking population movements with mobile phone network data: a post-earthquake geospatial study in Haiti. PLoS Med 8:e1001083

7. Lu X, Bengtsson L, Holme P (2012) Predictability of population displacement after the 2010 Haiti earthquake. Proc Natl Acad Sci USA 109:11576-11581

8. Wang P, Hunter T, Bayen AM, Schechtner K, González MC (2012) Understanding road usage patterns in urban areas. Sci Rep 2:1001 
9. Isaacman S, Becker R, Cáceres R, Kobourov S, Martonosi M, Rowland J, Varshavsky A (2011) Identifying important places in people's lives from cellular network data. In: Proc. of the 9th international conference on pervasive computing, pp 133-151

10. Wang H, Calabrese F, Di Lorenzo G, Ratti C (2010) Transportation mode inference from anonymized and aggregated mobile phone call detail records. In: Proc. of the 13th international IEEE conference on intelligent transport systems, pp 318-323

11. Lima A, De Domenico M, Pejovic V, Musolesi M (2013) Exploiting cellular data for disease containment and information campaigns strategies in country-wide epidemics. Technical report CSR-13-01, School of Computer Science, University of Birmingham

12. Amini A, Kung K, Kang C, Sobolevsky S, Ratti C (2013) The differing tribal and infrastructural influences on mobility in developing and industrialized regions. In: Proc. of 3rd int. conference on the analysis of mobile phone datasets

13. Berlingerio M, Calabrese F, Di Lorenzo G, Nair R, Pinelli F, Sbodio M (2013) AllAboard: a system for exploring urban mobility and optimizing public transport using cellphone data. In: Blockeel H, Kersting K, Nijssen S, Železný F (eds) Machine learning and knowledge discovery in databases, lecture notes in computer science. Springer, Heidelberg

14. Tatem AJ, Noor AM, von Hagen C, Di Gregorio A, Haym SI (2007) High resolution population maps for low income nations: combining land cover and census in East Africa. PLoS ONE 2:e1298

15. Gastner MT, Newman MEJ (2004) Diffusion-based method for producing density-equalizing maps. Proc Natl Acad Sci USA 101:7499-7504

16. Dorling D, Newman MEJ, Barford A (2010) The atlas of the real world: mapping the way we live, 2 nd edn. Thames \& Hudson, London

17. Gastner MT, Newman MEJ (2006) Optimal design of spatial distribution networks. Phys Rev E 74:016117

18. Gastner MT (2011) Scaling and entropy in p-median facility location along a line. Phys Rev E 84:036112

19. Schläpfer M, Bettencourt LMA, Raschke M, Claxton R, Smoreda Z, West GB, Ratti C (2012) The scaling of human interactions with city size. arXiv:1210.5215

20. Warton DI, Wright IJ, Falster DS, Westoby M (2006) Bivariate line-fitting methods for allometry. Biol Rev 81:259-291

21. Arcaute E, Hatna E, Ferguson P, Youn H, Johansson A, Batty M (2013) City boundaries and the universality of scaling laws. arXiv:1301.1674

22. Aker JC, Mbiti IM (2010) Mobile phones and economic development in Africa. J Econ Perspect 24:207-232

23. Roeth $H$, Wokeck L (2011) ICTs and climate change mitigation in emerging economies. Technical report. Available at http://www.niccd.org/sites/default/files/RoethWokeckClimateChangeMitigationICTs.pdf

24. Paul DI, Uhomoibhi J (2012) Solar power generation for ICT and sustainable development in emerging economies. Campus-Wide Inf Syst 29:213-225

25. Schien D, Shabajee $P$, Yearworth M, Preist C (2013) Modeling and assessing variability in energy consumption during the use stage of online multimedia services. J Ind Ecol 17:800-813

26. Schien D, Shabajee P, Wood SG, Preist C (2013) A model for green design of online news media services. In: Proc. of the 22nd international world wide web conference

27. Vodafone Group (2011) Sustainability report

28. Oh E, Krishnamachari B, Liu X, Niu Z (2011) Toward dynamic energy-efficient operation of cellular network infrastructure. IEEE Commun Mag 49:56-61

29. O2 (2011) O2 Sustainability report

30. Vodafone Deutschland (2011) Corporate responsibility report 2010/2011

31. Vodafone Group (2012) Sustainability report. Available at http://www.vodafone.com/content/dam/vodafone/about/ sustainability/reports/2011-12/vodafone_sustainability_report_2011-12.pdf

32. GSMA (2012) Mobile's green manifesto. Technical report

33. Abidjan.net (2012) Téléphonie mobile : Les parts de marché de chaque entreprise. Available at http://news.abidjan.net/h/435550.html

34. Liberation (2012) La Côte-d'Ivoire, un terrain trop mobiles. Available at http://www.liberation.fr/economie/2012/05/28/la-cote-d-ivoire-un-terrain-trop-mobiles_822054

35. World Bank (2009) World development indicators. Available at http://data.worldbank.org/data-catalog/world-development-indicators

36. data base Electric power consumption (kWh) in Cote d'Ivoire. Available at http://www.tradingeconomics.com/cote-d-ivoire/electric-power-consumption-kwh-wb-data.html

37. Wikipedia (2011) Vodafone

38. Statistisches Bundesamt (2011) Erzeugung

39. Sovacool BK (2008) Valuing the greenhouse gas emissions from nuclear power: a critical survey. Energy Policy $36: 2950-2963$

40. World Bank (2007) Cameroun : Plan d'Action National Energie pour la Réduction de la Pauvreté. Technical report

41. BBC News (2008) How much does it cost to operate a street light? Available at http://news.bbc.co.uk/1/hi/magazine/7764911.stm

42. Bundesministerium für Wirtschaft und Technologie (2011) Energieverbrauch des Sektors Gewerbe, Handel, Dienstleistungen (GHD) in Deutschland für die Jahre 2007 bis 2010

43. Malmodin J, Moberg Å, Lundén D, Finnveden G, Lövehagen N (2010) Greenhouse gas emissions and operational electricity use in the ICT and entertainment \& media sectors. J Ind Ecol 14:770-790

44. Nokia Nokia 108 dual sim specifications. Available at http://www.nokia.com/mea-en/phones/phone/108-dual-sim/specifications/

45. GSMA (2012) Sub-Saharan Africa mobile observatory 2012. Technical report

46. González MC, Hidalgo CA, Barabási A-L (2008) Understanding individual human mobility patterns. Nature 453:779-782

47. Noulas A, Scellato S, Mascolo C, Pontil M (2011) Exploiting semantic annotations for clustering geographic areas and users in location-based social networks. AAAI Workshop - Technical report, pp 32-35

48. Noulas A, Scellato S, Lambiotte R, Pontil M, Mascolom C (2012) A tale of many cities: universal patterns in human urban mobility. PLoS ONE 7:e37027 
49. Becker RA, Cáceres R, Hanson K, Meng Loh J, Urbanek S, Varshavsky A, Volinsky C (2011) Route classification using cellular handoff patterns. In: Proc. of the 13th international conference on ubiquitous computing, pp 123-132

50. Isaacman S, Becker R, Cáceres R, Kobourov S, Rowland J, Varshavsky A (2010) A tale of two cities. In: Proc. of the 11th workshop on mobile computing systems, pp 19-24

51. Quercia D, Di Lorenzo G, Calabrese F, Ratti C (2011) Mobile phones and outdoor advertising: measurable advertising. IEEE Pervasive Comput 10:28-36

52. Lucet J-C, Laouenan C, Chelius G, Veziris N, Lepelletier D, Friggeri A, Abiteboul D, Bouvet E, Mentré F, Fleury E (2012) Electronic sensors for assessing interactions between healthcare workers and patients under airborne precautions. PLOS ONE 7:e37893

doi:10.1140/epjds21

Cite this article as: Salnikov et al.: The geography and carbon footprint of mobile phone use in Cote d'Ivoire. EPJ Data Science 2014 3:3.

Submit your manuscript to a SpringerOpen ${ }^{\circ}$ journal and benefit from:

- Convenient online submission

Rigorous peer review

- Immediate publication on acceptance

- Open access: articles freely available online

- High visibility within the field

- Retaining the copyright to your article

Submit your next manuscript at $>$ springeropen.com 